\title{
Modelling owner's physiognomies \& incitements for the adoption of enterprise application architecture for supply chain management in small and medium enterprises: A case of Capricorn District Municipality
}

\author{
Kingston Xerxes Theophilus Lamola \\ Department of Business Management \\ University of Limpopo, South Africa
}

\begin{abstract}
Keywords
Enterprise application architecture, owner's physiognomies \& incitements, security architecture design, small and medium enterprises, supply chain management, and theory of reasoned action

Abstract

The adoption of enterprise application architecture (EAA) for supply chain management (SCM) in small and medium enterprises (SMEs) was influenced by the owner's physiognomies and incitements (OPIs) on a routine basis. The study employs a quantitative approach based on a linear regression model, which uses diagnosis tests "Cronbach's Alpha, normal distribution, and Kolmogorov-Smirnov test" that makes descriptive statistics possible on Pearson correlations, analysis of variance (ANOVA), Pearson's Coefficients, and linear regression. The study examines whether OPIs affect the adoption of EAA for SCM in SMEs within Capricorn District Municipality. The paper exploits the original data set of 310 SMEs, targeting predominantly both SMEs' owners and managers to run linear regression models with the dependent variable "actual adoption of EAA" and independent variable "OPIs". A novel piece of authenticity for the models is the incorporation of OPIs within the SCM activities and whether there were any, collaborative influences affecting the adoption of EAA. The findings have a bearing on SMEs' SCM growth strategies, directed towards the technology acceptance model.
\end{abstract}

Corresponding author: Kingston Xerxes Theophilus Lamola

Email addresses for the corresponding author: kingston.lamola@ul.ac.za

The first submission received: $17^{\text {th }}$ July 2021

Revised submission received: $28^{\text {th }}$ October 2021

Accepted: $3^{\text {rd }}$ November 2021

\section{Introduction}

The Owner's Physiognomies \& Incitements (OPIs) plays a significant role in the adoption of EAA for SCM within SMEs. Numerous algorithms are used for programming enterprise systems for SCM in the Fourth Industrial Revolution (4thIR). According to Stok, Renner, Allan, Being, Ensenauer, Issanchou, Kiesswetter, Lien, Mazzochi, Monsivais, Stelmach-Mardas, Volkert \& Hoffmann (2018), entrepreneurs who are passionate about surviving difficult times, although internal and external environmental obstacles manifest with minimal economic benefits, manage SMEs that survive with a coherent overview that requires effective synthesis of the existing knowledge across different disciplines. Focusing on the OPIs is an essential principle that induces perceived attitudes on three dimensions, such as alternative user-base solutions, resistance to change, and technological aversion (Merritt, 2019; Law Insider, 2019). Since many researchers focus on corporate sectors, the current literature on the adoption of EAA for SCM in SMEs is severely underdeveloped (Hazen, Kung, Cegielski \& Jones-Farme, 2014; Iyamu \& Mphahlele 2014; Ingram 2018). According to Ghosh (2015a), Ghosh (2018b), and Jenkin (2016), SMEs with selfleadership benefit from a positive creativity climate that leverages synergistic creativity and innovation to provide a long-term competitive advantage. As a result, SMEs should regard themselves as ideal EAA for SCM adapters since they operate in a challenging, diverse, and competitive world of business expertise. SMEs in Capricorn District Municipality has numerous challenges, including a lack of financial viability, a lack of formal education, and a lack of technical skills.

There is a wake-up call for SMEs to invest in technology infrastructure for effective SCM operations, such as insourcing, process outsourcing, and so on (Poba-Nzaou, Raymond \& Fabi 2014; Ticlo 2018). By considering the economic nature of the environment in which SMEs operate, there is a need to consider 
critical issues for a better environment for EAA adoption. It consists of reliability, excellence, value, expertise, problem-solving skills, continuous improvement, support, a positive attitude, a global reach, and strong relationships that lead to optimum production within SMEs (Bowman 2020). In today's competitive business world, customer relationship management systems (CRMS) assist enterprises in growing by developing relationships with their customers through loyalty and customer remembrance developed for SCMS and long-term connections (Cognite, 2018).

\section{Statement of the research problem}

Increased demand-driven sales planning triggers mechanisms in other operations. This is an issue for a synchronised SCM in SMEs in meeting increasingly high customer-service demands, which is a major concern among SME owners and has piqued the interest of scholars. There are numerous questions with exceptional responses based on OPIs that influence EAA adoption. As a result, many small and mediumsized business owners are unaware of the nature and purpose of EAA. The quality of EAA's SCM is surrounded by many assumptions and forecasts, which contribute to a significant failure rate in SMEs due to inadequate SCM. A large number of researchers support this problem statement (Power, 2008; Morosan 2011; Schulz \& Dankert 2016). This could be an indication of SMEs' reluctance to adopt EAA because of OPIs changing aspects in; decision support systems, regulatory laws, and dynamics in biometric systems (Stok et al. 2018; Broughton 2018; Hendricks 2018). In a study, Valasseri (2019) finds that only 95\% of organisations face challenges with the technology they have chosen to strengthen their business objectives.

\section{Aim}

The purpose of this paper is to provide a conceptual theoretical framework based on OPIs for the adoption of EAA in SMEs within Capricorn District Municipality, as well as to assess the extent to which it occurs.

\section{Objectives}

The key objective is to examine whether the physiognomies of the owners influence the adoption of EAA in SMEs for SCM.

Subsequently, the secondary objective is to explore hidden parameters that would make it possible to unambiguously, predict orthodox procedure to produce the result of specific characters within the adoption of EEA in SMEs for SCM.

\section{Literature Review}

\section{Theoretical review: Theory of Reasoned Action (TRA)}

The existing literature focuses on user conduct when using EAA. Aside from the circumstances surrounding EAA adoption, the TRA and Theory of Planned Behaviour (TPB) specify a limited number of psychological factors (Dillon \& Morris 1996a; Albarracn, Blair, Johnson, Fishbein \& Muellerleile 2001). In this study, the term TRA is broadly defined as the predictive validity for establishing the predictive validity as a comprehensive model of behaviour (Blair, Johnson, Fishbein \& Muellerleile 2001; Dillon \& Morris 2018b). This theme came up, for example, in discussions of a number of deterrents to EAA adoption, including intention, attitude toward behaviour, subjective norm, perceived behavioural control, and behavioral-normative control beliefs (Albarracn et al. 2001). The TAM is based on the TRA and predicts employee behaviour in specific situations and circumstances, such as the adoption of EAA for SCM (Ajzen \& Fishbein 1977; Stam, Stanton \& Guzman 2004; Hui, Cau, Lou \& He, 2014). Furthermore, Ajzen (1991) asserts that TRA implies that a person's behaviour is determined by their intention to act in some way because of subjective customs. Other authors, including Albarracín et al. (2001); Camadan, Reisoglu, Ursavas and Mcilroy (2018) and LaMorte (2018) alluded to a limited number of psychological variables that can influence a behaviour, such as intention; attitude toward the behaviour; subjective norm; perceived behavioural control; and with behavioural, normative and control belief. Silverman, Hanrahan, Haung, Rabinowitz, and Lim (2016) argue that by integrating systems science, agent modelling and simulation, knowledge management architecture, and domain theories, EAA adoption could be facilitated. TRA distinguishes two types of perceived behavioural control that can have a direct predictive effect on behaviour via two distinct mechanisms (Ajzen, 1991): 
Keeping intention constant, an employee with higher perceived behavioural control is more likely to try harder and persevere for a longer period of time than an employee with lower perceived control; and

People may have accurate perceptions of their level of actual control over their behaviour.

According to Fishbein and Ajzen (1975) and Omale (2019), "In the past, subjective norms created several other options with the persuade for subjective norms that created several other options." Adopting a business-outcome-driven EA programme will help to strengthen a normative belief that supports the persuasive.

Increase the motivation to comply with a norm that supports the persuasive goal.

Reduce a normative belief that opposes the persuasive goal, start with business architecture.

Reduce the motivation to comply with a norm that opposes the persuasive goal and determine organisational design.

Create a new subjective norm that supports the persuasive goal, determine skills set and staffing, and determine governance and assurance; and

Remind the audience of a forgotten subjective norm that supports the persuasive goal, determine business value metrics and construct a charter.

These arguments, taken together, provide important insights into TRA, assisting enterprises in predicting the acceptability of a tool based on internal factors such as perceived usefulness and perceived ease of use. Furthermore, to identify the hardware and software modifications for ease of use for both internal and external users, which must be introduced into the system in order for it to be acceptable to users.

\section{Conceptual review}

Much of the recent literature on SCM focuses specifically on the use of EAA. EAA entails the process of exemplifying the coordinating-computer paradigms by incorporating an organisation's information technology assets to form the computing infrastructure that sustains business goals (McComb, 2004). This section summarises the literature review that was used to structure the variables in the questionnaire for this survey. One of the global issues that SMEs face is the adoption of EAA. There is a significant relationship between OPIs and the use of EAA for SCM operations such as insourcing, processing, and outsourcing (Smit 2017; Herman \& Stefanescu 2017), which determine the highest level of efficiency (Sebetci 2019). According to the literature, SMEs face challenges in the following areas: distribution network configuration, access flexibility, number of participants, geographical allocation, suppliers' networks, manufacturing facilities, distribution centres, warehouses, customer relations, and distribution strategies (Nair 2010; Stet 2014). This means that without EAA, neither SCM success nor production efficiency will be provided. According to Hon and Lui (2016), SMEs' owners are increasingly realising the value of integrating their psychographics and behavioural motivations, as well as their creativity. It is thus critical for SMEs that have been transformed into modern enterprises to study the environmental supply chain dynamics and understand how the disruption-driven ripple effect may influence the dynamics of the bullwhip effect (Dolgui, Ivanov \& Rozhkv 2019).

SMEs are seeing transformation in technology innovation by aligning innovation with agility. Furthermore, SMEs gain a competitive advantage in SCM by developing a statutory framework that defines all of the roles, responsibilities, and relationships involved in program management and information technology operations (Asetpartners 2018). Chang, Lakovou, and Shi (2019) contend that a smart investment in blockchain could reduce the level of uncertainty and risk associated with the use of EAA for SCM. With the growth of EAA, SMEs are looking for application software that will provide them with a customised and one-of-a-kind experience that will be faultless in perpetuity. Furthermore, current SMEs are the adopters seeking an EAA program that will prepare them for effective SCM (Bawa, Buchholz, de Villiers, Corless \& Kaliner 2017). SME owners who have adopted EAA: EAA has enormous value in SMEs, particularly in terms of application performance smoothing, high scalability, and flexibility, easy integration of new features, cost savings, decreased development time, and high security (Le 2020; Pavlenko 2021). With the innovation-driven environment stretching far beyond traditional cyber, regulatory, operational, and financial challenges, SMEs should become more technologically oriented (Briggs, Buchholz \& Sharma 2020). According to Spence (2020), one of the most interesting developments in cognitive technology in recent decades has been the growing recognition that perception/experience is 
significantly more multimodal than other SMEs had realised. Dissatisfaction with the traditional approach in SCM drove the implementation of EAA. The main factors influencing the adoption of EAA for SCM in SMEs cost marginalisation through offshore development and total cost of ownership considerations (Schmidt, 2013). Using the lens model as a framework, Gifford, Hine, Muller-Clemm, and Shaw (2002) investigated the relationship between the enterprise physical qualities of buildings, the perceptions of "attractive" and "pleasurable," and the subject's overall assessment. According to the findings, both groups based their emotional assessments on completely different building elements. SMEs, on the other hand, are becoming more traditional in their approach to SCM, while SCM partners on facilities are becoming more prominent. Researchers and enterprise practitioners are drawn to EAA adoption for the following reasons: simplicity, succinct but not imperceptible, standardised way of doing things, outstanding supporting tools, short feedback loops, expressiveness, and excellent third-party packages (Young 2012).

Based on cost considerations, it is believed that the adoption of EAA is a critical factor in the performance of SMEs in SCM. Employee productivity surpasses cost, business speed outperforms employee productivity, and security outpaces business speed (Settle 2019). Furthermore, it was discovered that the implementation of EAA in many developed and developing economies has increased customer satisfaction and changed the way SMEs approach their internal and external activities. A welldesigned enterprise architecture enables SMEs to achieve consensus from all internal and external stakeholders. This is achieved through support planning, change facilitation, complexity management, risk reduction, and technical debt minimisation, all of which are the goals of any well-designed architecture (Menezez 2020). Physiognomies and incitements: It have been discovered that the adoption of EAA that provides the features of a well-encyclopaedic SCM in trendy, sustainable, and self-regulating ways with a computerisation guarantee is effective. However, Ashanti (2018) classifies twelve EAA criteria for SCM activities in SMEs that are linked to quality work output:

Application Performance Review - Application performance review encrypted in EAA aids in SCM tasks by evaluating its performance and scalability attributes via the application's performance characteristics, which are determined by the application's architecture and design (Daya 2019; Le 2020). On completion of EAA, the process of agile model specification and parameter estimation could be executed for possible adoption of EAA. Suggestion from the implementation of EAA suggests that OPIs when combined with APR, improve SCM performance.

Scalability Web Application - Scalability Web application is encoded in a website that assists SMEs in dealing with any marginal increase or decreases in production facilities for a gradual or abrupt surge, without interfering with end-user activities and with the ability to rapidly intensify the load in SCM (Daya 2019; Le 2020). One major theoretical issue that has dominated the field for many years concerns the implementation of the continuous-flow model that offers stability whilst facing high demand. In general, it appears that SWA could handle any increase in users and load, whether gradual or abrupt, without disrupting end users' SCM activities.

Interoperability Syntactic (IS) - Interoperability syntactic is considered for disseminating message successfully with tools that provide syntactic interoperability for formatting standards in SCM, also known as structural interoperability (Lewis 2019). To date, there has been little agreement on what continuous flow model could offer the level of stability in SCM in high demand market-facing minimum fluctuations. These definitions suggest that IS allows multiple systems to exchange data from different locations; however, the interface and programming languages may differ. Nonetheless, as interoperability becomes more common, proactive sharing of implementation concepts and practices is essential for SMEs to be more agile in their SCM activities.

Usability - According to the findings of a study conducted by Capilla, Kazman, Romera, and Carrillo (2020), the organisation of numerous usability mechanisms appears helpful for end-users by offering compatibility of mobile systems that promote satisfaction during the engagement with the system and thus in SCM. One major issue in early OPIs research concerned the custom configuration model that provides custom configurations at both manufacturing and assembly phases. This has the implication that it describes a system's ability to provide users with informed conditions when confronted with risk in software applications such as schedule risk, budget risk, operational risk, technical risk, and programmatic risk. 
Reliability - The reliability of SCM considers the aspect of the system that is responsible for the system's ability to continue operating under predetermined conditions (Tomaney 2010). The reliability of SMEs in SCM is envisioned as a distinct field of specialisation that guarantees applications that are developed to supply essential SME's functionality in a reliable, predictable, and cost-effective manner without compromising essential features such as availability, performance, and maintainability (Sha 2020). The issue has grown in importance in light of recent developments in efficient chain-model that focus on competitive markets. The importance of OPIs, supported by current findings that software reliability modelling denotes that in a matured EAA, the results obtained by applying appropriate models to the problem such as size and complexity of code, characteristics of the development process used, education, experience, and training of development personnel, and operational environment.

Availability - In this context, availability includes a number of components that work together to ensure continuous service for a given period in SCM. It also covers the response time to end-user queries in SCM with available systems that are highly responsive when connected to the internet. Furthermore, the absence of flaws with a level of usability has no bearing on the operations of SMEs (Jevtic 2018). One observer has already drawn attention to the paradox in the fast chain model for enterprises that are flexible and have a marginal short-life cycle. According to the findings of the OPI investigation, application-specific key performance indicators such as timed application uptime and downtime, number of completed transactions, responsiveness, reliability, and other relevant metrics determine EAA availability.

Security Architecture Design - Security Architecture Design denotes that the level of security architecture in modern information and communications technology systems is critical, which is controlled by architect specialists on technical elements for secure SCM (Kien 2020). Questions are raised about the safety of prolonged use of a flexible model that provides an opportunity to satisfy high-demand peaks and manage long periods at low volumes. Furthermore, the security architecture's robust elements, as well as the design of the proactive portions, rely on full and consistent design to ensure that incident detection, response, and recovery do not interfere with SCM activities. While this study did not confirm OPIs, it did partially substantiate SAD's focus on the selection and composition of components that form the foundation of SMEs solutions, with a particular emphasis on their security properties.

Maintainability Applications - In reference to maintainability applications, EAA necessitates the upkeep and testing of standards that accelerate change in order to acquire or maintain a competitive edge, making SMEs aware that a high-profile system failure could result in both lost income and failure to meet the market target in SCM (Tomany 2020; Wayner 2020). In many MAs', a debate is taking place between EAA and SC concerning operations reference models that assess waste, establishes standards, and encourages continuous improvements in the SCM system. Maintainability applications to make description an advantage in those who use the maintainability analysis, which provides calculated information on various aspects of owner's physiognomies and incitements.

Modifiability - Enterprises that modify EAA in SCM determine the system's ability to influence a single item, which may be difficult, if not impossible if a number of actions rely on it (Wayner 2020). Mäkitalo, Taivalsaari, Kiviluoto, Mikkonen \& Capilla (2020) propose that system developers build and reuse code modules in SCM for future changes to a systematic algorithm. The controversy about scientific evidence for OPIs has raged unabated for over a century with Supply models are similar in so many ways because they all have similar goals that include marginalizing costs, reduce risk, satisfy the-end-users, enhancing productivity. For the first time, this study demonstrated that an analysis of modifiability strategies structured to predict future changes revolving the software system on cost of change and embedded in enterprise concerns for predicting future changes.

Testability - Testability for EAA in SCM refers to the level of accountability for carrying out tests, measured against predetermined criteria and result in a fully functional system (Wayner 2020). This concept has recently been challenged by OPIs studies demonstrating the architecture of a typical enterprise resource planning system that includes connectivity, web-enablement, modelling, and optimization. One major theoretical matter that has dominated the field for many years' concerns; information technology infrastructure that involves; interface devices and technology, auto-ID technology-communication system, technology, and system architecture for SCM. The analysis of OPIs 
performed has expanded our knowledge of testability if the software artefact is high, as discovering faults in the system would be easier at that time.

Reusability - Reusability is concerned with the ability to reuse a specific component or encrypted in SCM on assets associated with EAA that scale an opportunistic design (Mäkitalo et al. 2020). The causes of OPIs have been the subject of intense debate within the scientific community where; cost savings, informed purchasing decisions, reduction in RSA downtime, message-pops notifications, and increased productivity are of paramount importance in SCM. As it reflects design features that enhance its suitability for reuse, the methods used for this reusability are applied to other applications elsewhere in the enterprise operations.

Supportability - The ability of EAA and the system to provide useful information for identifying and resolving problems in SCM through enterprise operations is referred to as supportability (Settle 2019). The issue of supportability has been a controversial and much-disputed subject within the field of application architecture that prompt the understanding of information technology service and support processes that nature competitive advantage creates efficiencies and add value to the business. Taken together, these delineations suggest that supportability may play a role in promoting the adoption of EAA for SCM in SMEs.

\section{Research Methodology}

In this study, a quantitative survey method was developed to collect primary data. Created and tested a questionnaire to ensure data accuracy and the intended results. Self-administered questionnaires with a Likert scale were used to collect data. A total of 310 people were chosen using a non-probability sampling method. Questionnaire design: The questionnaire was composed of Likert scale questions and respondents were given five possibilities from rating scales with a range of described classifications that reflected a variety of responses. Each set of questions was designed to achieve the study's research objective(s). As a tool for framing questions, coding, and analysing data, the Likert scale performed admirably. There was no ambiguity in the questionnaire development to ensure that respondents had a clear understanding.

\section{Questionnaire development}

In this section of the questionnaire, respondents were asked to provide information on the OPIs, as well as the actual adoption of EAA questions. Originally, the questionnaire included eight mandatory categories, used in this publication from the OPIs (table 1) as well as the actual adoption of EAA (table 2).

\section{OPIs \& incitements questions}

To measure OPIs, a questionnaire was, developed and six constructs were tested. The respondents requested to express their experience about the following aspects on OPIs on the adopting EAA for SCM.

\begin{tabular}{|c|c|c|c|c|c|c|}
\hline 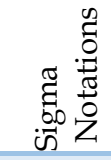 & Please tick an appropriate box $(\checkmark)$ from 1.1 to 1.6. & 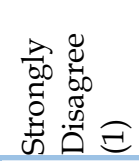 & 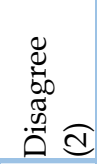 & 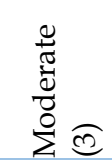 & 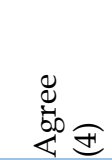 & 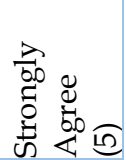 \\
\hline 1.1) & $\begin{array}{l}\text { Demonstrate passion for being successful with the } \\
\text { business. }\end{array}$ & (1) & (2) & (3) & (4) & (5) \\
\hline 1.2) & Try out new ideas in the business. & $(1)$ & $(2)$ & (3) & (4) & (5) \\
\hline 1.3) & Set goals and guidelines to achieve them. & (1) & $(2)$ & (3) & (4) & (5) \\
\hline 1.4) & Demonstrate passion for hard work. & (1) & $(2)$ & (3) & (4) & (5) \\
\hline 1.5) & $\begin{array}{l}\text { Ignore distractions and focus on the immediate } \\
\text { challenges. }\end{array}$ & $(1)$ & $(2)$ & (3) & $(4)$ & (5) \\
\hline 1.6) & Demonstrate "fight back" when problems threaten. & $(1)$ & $(2)$ & (3) & (4) & (5) \\
\hline
\end{tabular}

Table 1: Owner's Physiognomies \& Incitements Source: Author Conceptualisation

\section{Actual adoption of enterprise application architecture questions}

Respondents provided their assessments and opinions on the following assertions regarding the actual adoption of EAA for SCM. 


\begin{tabular}{|c|c|c|c|c|c|c|}
\hline 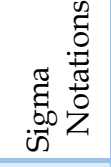 & 2.1 to 2.6 Please tick an appropriate box $(\checkmark)$ from & 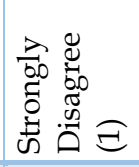 & 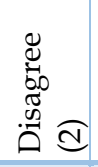 & $\begin{array}{l}\frac{0}{\pi} \\
\stackrel{0}{0} \\
\stackrel{0}{0} \widehat{C}\end{array}$ & 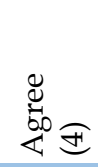 & 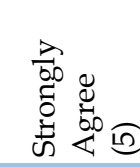 \\
\hline 2.1) & $\begin{array}{l}\text { Information Technology improves my job } \\
\text { satisfaction. }\end{array}$ & (1) & (2) & (3) & (4) & (5) \\
\hline 2.2) & $\begin{array}{l}\text { Information Technology supports all aspect of my } \\
\text { job requirement. }\end{array}$ & (1) & (2) & (3) & (4) & (5) \\
\hline 2.3) & $\begin{array}{l}\text { Information Technology allows me to accomplish } \\
\text { more work than in manual process. }\end{array}$ & (1) & (2) & (3) & (4) & (5) \\
\hline 2.4) & $\begin{array}{l}\text { Information Technology simplifies my day-to-day } \\
\text { activities. }\end{array}$ & (1) & (2) & (3) & (4) & (5) \\
\hline 2.5) & $\begin{array}{l}\text { Information Technology highlights technical errors } \\
\text { for me. }\end{array}$ & (1) & (2) & (3) & (4) & (5) \\
\hline 2.6) & It makes workflow straightforward. & (1) & $(2)$ & (3) & (4) & (5) \\
\hline
\end{tabular}

Table 2: Actual adoption of enterprise application architecture Source: Author Conceptualisation

\section{Stability Diagnostic Tests}

Normality test for variables

The evidence, which was tested using the descriptive statistical technique for the OPIs, was arranged to contribute to a further statistical examination of the Linear Regression model. As shown in Table 3 and Figure 1, the Cauchy normal distribution was transformed into asymmetric distribution with wellbehaved tails. This is indicated by a mean $(\mu) @ 22.81$, standard deviation $(\sigma) @ 3.263$, and the N @ 310.

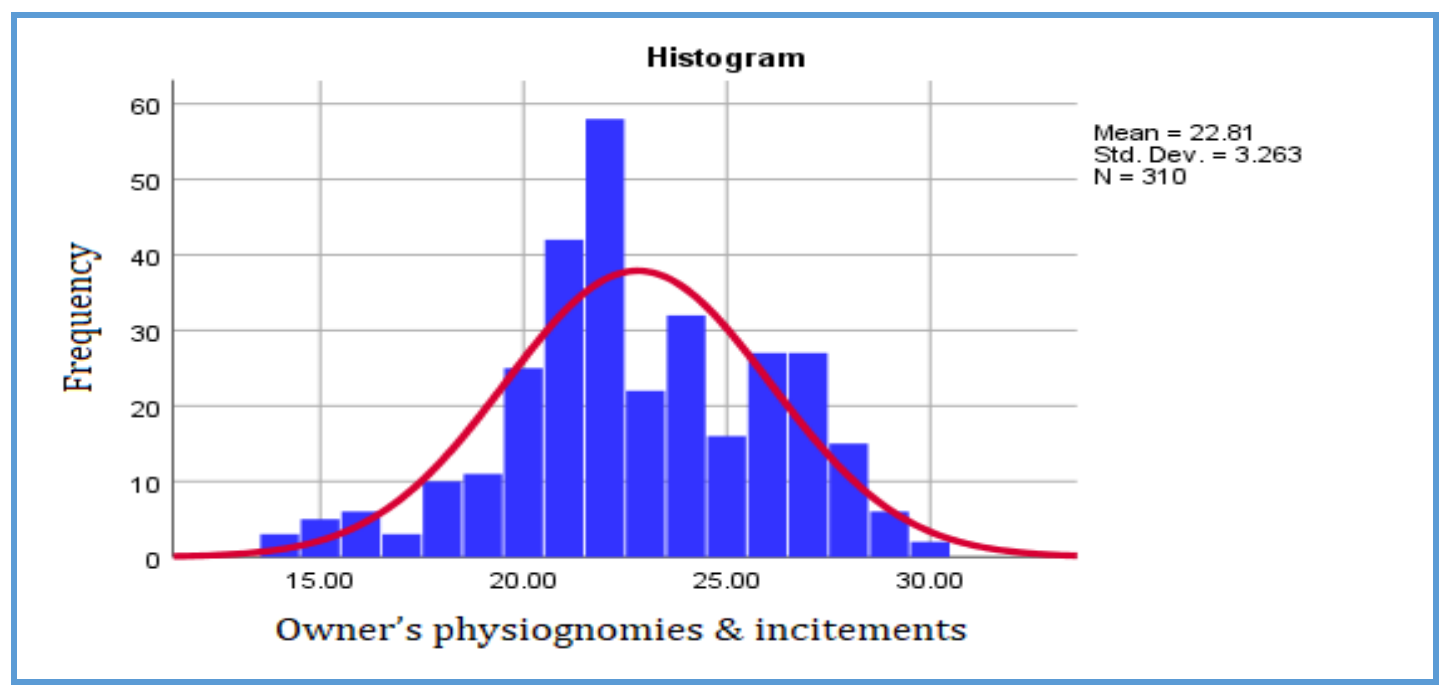

Figure 1: Normal Distribution on Owner's Physiognomies \& Incitements Source: Author Conceptualisation

OPIs resulted in a positive skewness of -.196 and Kurtosis of -.141. Kurtosis is zero for the standard normal distribution, negative Kurtosis for a "peaked" distribution, and negative Kurtosis for a "flat" distribution. The Kurtosis figure should be close to zero, and the value of -.141 indicates that it is a normal distribution that is slightly skewed to the left. As the $\mu$ is 0.228 and the median is 0.220 , the distribution is symmetric. This means that the model has the best match for homoscedasticity.

\section{Kolmogorov-Smirnov test for normality of OPIs}

Table 3 shows the results of the Kolmogorov-Smirnov test for the normality of OPIs, which show that they do follow a normal distribution, $\mathrm{D}(310)=0.123$ which is greater than $\mathrm{p}=0.05$. 
Table 3: Kolmogorov-Smirnov and Shapiro-Wink Test on OPIs

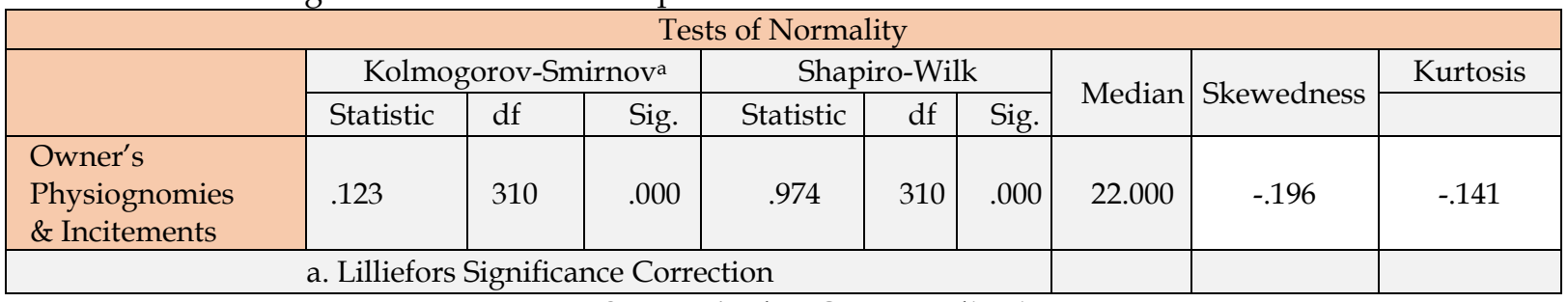

Source: Author Conceptualisation

The confirmation process led to the conclusion that the OPIs were statistically examined using a Linear Regression Model to examine the relationship between the OPIs and the Actual Adoption of EAA in SMEs for SCM.

\section{Research Findings}

Pearson Correlations on OPIs and actual adoption of EAA

Table 4 demonstrates the results on correlations between OPIs and Actual Adoption of EAA. The pvalue is near zero at " $<.001$ " with the required value set at 0.05 . The statistical technique "ANOVA" tested the hypotheses between the dependent variable, namely, Actual Adoption of EAA, and the independent variable, namely OPIs indicated in Table 1.

Table 4: Pearson Correlations on OPIs and actual adoption of EAA Pearson Correlations

\begin{tabular}{|c|c|c|c|}
\hline & & $\begin{array}{l}\text { Actual Adoption } \\
\text { of } \\
\text { EAA }\end{array}$ & Owner's Physiognomies \& Incitements \\
\hline \multirow{3}{*}{ Actual Adoption of EAA } & Pearson Correlation & 1 & $.185^{\star *}$ \\
\hline & Sig. (2-tailed) & & .001 \\
\hline & $\mathrm{N}$ & 310 & 310 \\
\hline \multirow{3}{*}{$\begin{array}{l}\text { Owner's Physiognomies } \\
\text { \& Incitements }\end{array}$} & Pearson Correlation & $.185^{\star *}$ & 1 \\
\hline & Sig. (2-tailed) & .001 & \\
\hline & $\mathrm{N}$ & 310 & 310 \\
\hline
\end{tabular}

Pearson Correlation Coefficients are .185, indicating a positive relationship between OPIs and Actual EAA Adoption. The association findings indicate that, in general, there is a positive relationship between OPIs and the actual Adoption of EAA with the sign change in mind.

\section{ANOVA on OPIs and actual adoption of EAA}

Table 5 confirms the ANOVA results for OPI scores and Actual Adoption of EAA. The independent variable is known as OPIs, and the dependent variable is known as Actual.

Table 5: ANOVA on OPIs and actual adoption of EAA

\begin{tabular}{|c|c|c|c|c|c|c|}
\hline \multicolumn{7}{|c|}{ ANOVAa $^{a}$} \\
\hline \multicolumn{2}{|l|}{ Model } & Sum of Squares & $\mathrm{df}$ & Mean Square & $\mathrm{F}$ & Sig. \\
\hline \multirow{3}{*}{1} & Regression & 122.708 & 1 & 122.708 & 10.925 & $.001^{\mathrm{b}}$ \\
\hline & Residual & 3459.563 & 308 & 11.232 & & \\
\hline & Total & 3582.271 & 309 & & & \\
\hline \multirow[t]{2}{*}{ A } & \multicolumn{6}{|c|}{ a. Dependent Variable: Actual Adoption of EAA } \\
\hline & \multicolumn{6}{|c|}{ b. Predictors: (Constant), Owner's Physiognomies \& Incitements } \\
\hline
\end{tabular}


Adoption of EAA. The general F-statistic is significant $(\mathrm{F}=10.925, \mathrm{p}<.001)$, thus signifying that the model accounts for a significant proportion of the variation in the adoption of EAA for SCM in SMEs. Since the exact significance level is $.001<\alpha$ at .05 , the results are statistically significant. The alternative sub- $\mathrm{H}_{\mathrm{a} 1}$ that; "OPIs affect the adoption of EAA for SCM in SMEs" is accepted, whilst the sub- $\mathrm{H}_{01}$ that; "OPIs does not affect the adoption of EAA for SCM in SMEs" is rejected.

\section{Pearson Coefficient on OPIs Incitements and Actual Adoption of EAA}

Table 6 shows the coefficient results for OPIs and Actual EAA Adoption. The t-test was used for testing because both samples had similar mean values in the mean @ 22.81 (as shown in Figure 1: OPIs have a normal distribution, and Table 3: The Kolmogorov-Smirnov and Shapiro-Wink tests on OPIs and actual EAA adoption).

Table 6: Pearson coefficients on OPIs and actual adoption of EAA

\begin{tabular}{|c|c|c|c|c|c|c|c|c|}
\hline \multicolumn{9}{|c|}{ Pearson Coefficients } \\
\hline \multirow{2}{*}{\multicolumn{2}{|c|}{ Model }} & \multicolumn{2}{|c|}{$\begin{array}{l}\text { Unstandardized } \\
\text { Coefficients }\end{array}$} & \multirow{2}{*}{$\begin{array}{l}\text { Standardized } \\
\text { Coefficients } \\
\text { Beta }\end{array}$} & \multirow{2}{*}{$\mathrm{T}$} & \multirow{2}{*}{ Sig. } & \multicolumn{2}{|c|}{$\begin{array}{l}\text { Collinearity } \\
\text { Statistics }\end{array}$} \\
\hline & & B & $\begin{array}{l}\text { Std. } \\
\text { Error }\end{array}$ & & & & Tolerance & B \\
\hline & (Constant) & 19.486 & 1.346 & & 14.47 & 1 & & \\
\hline 1 & $\begin{array}{l}\text { Owner's } \\
\text { Physiognomies } \\
\text { \& Incitements }\end{array}$ & .193 & .058 & .185 & 3.327 & .001 & 1.000 & 1.0 \\
\hline
\end{tabular}

In conditions where the predicted Ý consists of Perceived Attitudes towards the Adoption of EAA and OPIs with the score $=19.486+0.193^{*}$, then the $\mathrm{t}$-test shows that the $\hat{Y}$ constant $\mathrm{a}=0.193$ and the $\bar{Y}$ constant $b=119.486$ are significantly different from zero. The independent $t$-test could be used to determine the confidence interval of the coefficient, in case the $95 \%$ confidence interval for the $t$-test is [14.476, 3.327].

\section{Linear Regression on OPIs and actual adoption of EAA}

Figure 2 shows the results on $\bar{y}=$ assembled as Actual Adoption of EAA, where; $a=y$-axis intercept, $\mathrm{b}=+$ slope and $\mathrm{x}$-axis intercept are OPIs. This work naturally progressed to analysis.

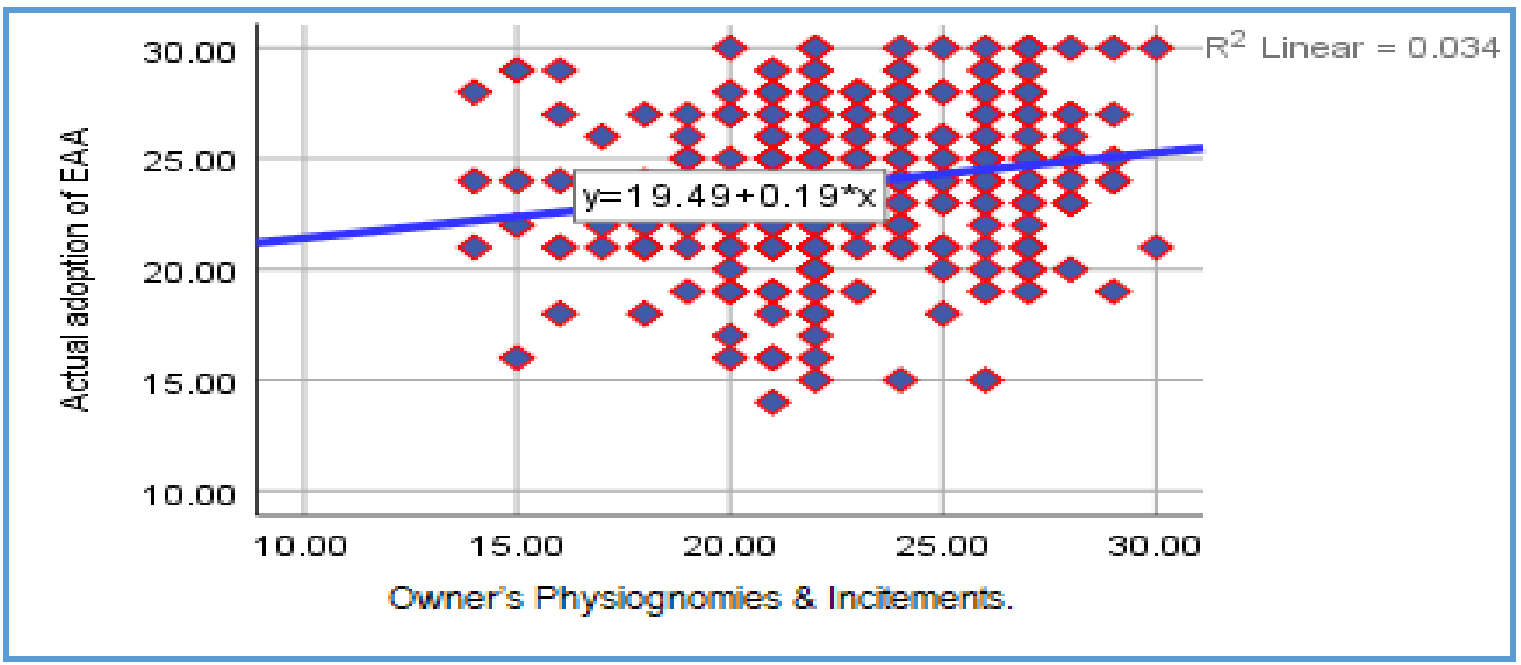

Figure 2: Linear Regression Model on OPIs and Actual Adoption of EAA Source: Author Conceptualisation 
The relationship between OPIs and actual SCM EAA adoption in SMEs. The $\mathrm{R}^{2}$ value is 0.034 of the variances is being accounted for in this scatter plot from the independent variable, as OPIs. The positive linear egression satisfies three of the best-fit model's assumptions, as shown in Figure 1. The linear regression where; $\overline{\mathrm{y}}=19.48+0.19^{*} \mathrm{x}$. The slope of +0.19 will bring the same increase in $\overline{\mathrm{y}}$. The $\mathrm{R}^{2}=0.034$ indicates that the level of variation in the prognostic variable could be described by variation in the independent variables. Moreover, the $\mathrm{R}^{2}$ is converted to $\mathrm{r}$ as; thus, $\sqrt{0.034}=0.184 \approx 0.185$ which is confirmed in Table 4 for Pearson Correlation Coefficients. This validates that the model is adequate with a positive slope and the model is of a positive fit between OPIs.

\section{Implications}

The findings contribute to the expansion of theoretical knowledge bases while also providing findings that will be of interest to SME owners, managers, and external SCM partners. However, the findings are limited to a single investigation using stratified random sampling. The sampling method allowed the researcher to choose each component from a specific group of SME owners and managers as targeted participants. The combination of findings lends some support to the conceptual premise that OPIs have improbable characteristics that influence SCM activities and EAA adoption. The implications of these outcomes highlight the complexities of EAA adoption, as highlighted in some discussions (Giovannoni \& Maraghini, 2013; Grigoriu, 2014; Faircloth, 2014; Arbesman, 2015). However, a significant flaw in this argument is that EAA algorithms and cost structures pose a challenge to SMEs seeking to theorise this phenomenon.

\section{Limitations}

There are several limitations to the study. First, while IRM is known in South Africa and internationally as a leading enterprise architecture value provider and authorised Sparx Systems Enterprise Architect license reseller, only a few SMEs will benefit from preferential procurement scores from level 2 Broad-based Black Economic Empowerment (BBBEE) status (Sparks Systems and Enterprise Architect, 2020). Second, it requires SMEs to determine which techniques will be used in practice to encourage EAA compliance (Foorthuis, van Steenbergen, Mushkudiani, Bruls, Brinkkemper \& Bos, 2020). Finally, it is possible that a large number of SMEs with ethical practices that comply with government regulations will be able to adopt EAA for SCM.

\section{Conclusions}

According to the findings of this study, OPIs influence the adoption of EAA for SCM in SMEs in Capricorn District Municipality. Both psychographic and behavioral incitements have a significant impact on general perceptions and attitudes, which may increase interest in EAA for SCM adoption in SMEs. Risk-averse SME owners will suffer significant losses in SCM unless they retract from the bleeding edge and are new-fangled. Hidden variables could be analogous to the relationship between OPIs (for example, collective and operational vulnerabilities) and mechanisms (the gestures of the individual traits).

\section{References}

Ahmad, N. \& Mehmood, R. 2015, Enterprise Systems: Are We Ready for Future Sustainable Cities? Supply Chain Management: An International Journal, (20)3: 264-283.

Ajzen \& Fishbein. (1980b); Fishbein \& Ajzen. (1975b). Theory of Reasoned Action.

http://www.cios.org/encyclopedia/persuasion/Gtheory_1reasoned.htm (accessed 5 September 2021).

Ajzen, I. \& Fishbein, M. 1977, "Attitude-Behavior Relations: A Theoretical Analysis and Review of Empirical Research". Psychological Bulletin, 84(5): 888-918.

Ajzen, I. 1991, The Theory of Planned Behaviour: Organisational Behavior and Human Decision Processes. A journal of fundamental research and theory in applied psychology. 50(2):179-211 (accessed: 4 June 2018).

Albarracín, D., Blair A.T., Johnson, B.T., Fishbein, J.M. \& Muellerleile, P.A. 2001, Theories of Reasoned Action and Planned Behaviour as Models of Condom Use: A Meta-Analysis.

https://www.ncbi.nlm.nih.gov/pmc/articles/PMC4780418/, (accessed: 4 June 2018).

Alziari, L. 2017, A Chief HR Officer's Perspective on Talent Management. Journal of Enterprise Effectiveness: People and Performance, (4)4:379-383.

Anderson, M. \& Perrin, A. 2017, Barriers to Adoption and Attitudes towards Technology.

http://www.pewinternet.org/2017/05/17/barriers-to-adoption-and-attitudes-towards-technology/ (accessed 26 February 2019). 
Arbesman, S. 2015, The Problem with Technological Ignorance: And Why We Need to Teach Abstraction. From: http:/ /www.slate.com/articles/technology/future_tense/2015/12/the_problem_with_technological_ign orance.html (accessed 4 August 2018).

Ardley, B., Moss, P. \& Taylor, N. 2016, Strategies Snarks and Stories: SMES Owner Manager Perceptions of Business Advisers. Journal of Research in Marketing and Entrepreneurship, (18)2: 211-231.

Arsalan, M.N. 2018, E-Commerce Adoption Factors Affecting the SMEs: A Case Study Investigation of a Developing Economy-Pakistan. Scholar Teesside University Business School Teesside, University United Kingdom.

Ashanti, N. 2018, 12 Software Architecture Quality Attributes. From: https://syndicode.com/blog/12-softwarearchitecture-quality-attributes/ (accessed 7 May 2021).

Bowman, R.J. 2020, 100 Great Supply Chain Partners: Meeting the Need for Speed. From:

https://www.supplychainbrain.com/articles/31697-great-supply-chain-partners-of-2020 (accessed 5 May 2021).

Briggs, B., Buchholz, S. \& Sharma, S. 2020, Delloite Insight. Tech Trends 2020. From:

https://www2.deloitte.com/content/dam/Deloitte/cz/Documents/technology/DI_TechTrends2020.pdf (accessed 7 May 2021).

Brinkmann, M. 2019, Firefox's New Web Compatibility Page. Ghacks. https://www.ghacks.net/2019/02/28/firefoxsnew-web-compatibility-page/ (accessed 02 April 2019).

Broughton, P.D. 2018, The Real Risk-Takers: What Makes an entrepreneur? From:

http://www.montroseassociates.biz/article.asp?aid=71/ (Accessed 21/03/2018).

Butterfield, V. 2017, Successful Entrepreneurs Believe in Themselves. https://venturecapital.org/successfulentrepreneurs-believe-in-themselves/ (accessed 12 June 2018).

Cadarette, M.S., Ban, K.J., aGiulia, J.K., Consiglio, P.G., Black, C.D., Dubins, D., Marin, A. \& Tadrous, M. 2017, Diffusion Of Innovations Model Helps Interpret The Comparative Uptake Of Two Methodological Innovations: Co-Authorship Network Analysis And Recommendations For The Integration Of Novel Methods In Practice. Science Direct. https://www.sciencedirect.com/science/article/pii/S0895435616308356 (accessed 02 April 2019).

Camadan, F., Reisoglu, I., Ursavas, Ö.F. \& Mcilroy, D. 2018, How Teachers' Personality Effect on Their Behavioural Intention to Use Tablet PC. The International Journal of Information and Learning Technology, (35) 1: 12-28.

Capilla, R., Kazman, R., Romera, C. \& Carrillo, C. 2020, Usability Implications in Software Architecture: The Case Study of a Mobile App. https://onlinelibrary.wiley.com/doi/abs/10.1002/spe.2883?af=R (accessed 7 May 2019).

Chang, Y., Lakovou, E. \& Shi, W. 2019, Blockchain in Global Supply Chains and Cross Border Trade: A Critical Synthesis of the State-Of-The-Art, Challenges and Opportunities. From:

https://www.tandfonline.com/doi/full/10.1080/00207543.2019.1651946 (accessed 6 May 2021).

Coulson-Thomas, C. 2012, Talent Management and Building High Performance Organisations. Industrial and Commercial Training, (44)7: 429-436.

Daya, V. 2019, Application Performance Review Process. From: https://dzone.com/articles/applicationperformance-review-process (accessed 7 May 2019).

DesMarais, C. 2014, Why Risk-Takers Do Better in Business and In Life? From: https://www.inc.com/christinadesmarais/why-risk-takers-do-better-in-business-and-life.html/ (accessed 21 March 2018).

Dillon, A. \& Morris, M. 1996a, User Acceptance of New Information Technology: Theories and Models. In M. Williams (Ed.) Annual Review of Information Science and Technology, (31), Medford NJ: Information Today, 3-32.

Dillon, A. \& Morris, M.G. 2018b,

https://www.ischool.utexas.edu/ adillon/BookChapters/User\%20acceptance.htmUser Acceptance of Information Technology: Theories and Models, (accessed: 27 April 2018).

Dolgui, A., Ivanov, D. \& Rozhkv, M. 2019, Does the Ripple Effect Influence the Bullwhip Effect? An Integrated Analysis of Structural and Operational Dynamics in the Supply Chain. From:

https:/ / www.tandfonline.com/doi/full/10.1080/00207543.2019.1627438 (accessed 6 May 2021).

Eckler, P. \& Bolls, P. 2011, Spreading the Virus: Emotional Tone of Viral Advertising and Its Effect on Forwarding Intentions and Attitudes. Journal of Interactive Advertising, 11(2): 1-11.

Poba-Nzaou, P., Raymond, L. \& Fabi, B. 2014, Risk of adopting mission-critical OSS applications: an interpretive case study. International Journal of Operations E Production Management 34(4):477-512.

Faircloth, J. 2014, Introduction to Enterprise Applications Administration. From:

https://www.sciencedirect.com/topics/computer-science/enterprise-application (accessed 06 February 2019).

Foorthuis, R., van Steenbergen, M., Mushkudiani, N., Bruls, W., Brinkkemper, S. \& Bos. R. 2020, On Course, But Not There Yet: Enterprise Architecture Conformance and Benefits in Systems Development. From: https://arxiv.org/abs/2008.11026 (accessed 21 May 2021).

Gao, Y. \& Hafsi, T. 2015, R \& D Spending Among Chinese SMEs: The Role of Business Owners' Characteristics. Management Decision, (53)8: 1714-1735. 
Genever, H. 2017, Why Risk-Takers Are Winners (and why all entrepreneurs should take risk). From: https://www.liveplan.com/blog/2017/02/why-risk-takers-are-winners-and-why-all-entrepreneurs-shouldtake-risks/ (accessed 21 March 2018).

Ghosh, B. 2018b, 10 Success Lessons from Sundar Pichai - "CEO of Google" for Entrepreneurs. http:/ / knowstartup.com/2018/02/10-success-lessons-sundar-pichai/ (accessed 9 May 2018).

Ghosh, K. 2015a, Developing Enterprises Creativity and Innovation: Toward A Model of Self- Leadership, Employee Creativity, Creativity Climate and Workplace Innovative Orientation. Management Research Review, (38)11: 11261148.

Gifford, R., Hine, D.W., Muller-Clemm, W. \& Shaw, K. T. 2002, Why Architects and Laypersons Judge Buildings Differently: Cognitive Properties and Physical Bases. Journal of Architectural and Planning Research, (19)2: 131-148.

Giovannoni, E. \& Maraghini, M.P. 2013, The Challenges of Integrated Performance Measurement Systems: Integrating Mechanisms for Integrated Measures. Accounting, Auditing \& Accountability Journal, (26)6: 978-1008.

Grigoriu, A. 2014, Enterprise Architecture Matters: What Business Problems Does Enterprise Architecture Solve? Ebizq. From: http://www.ebizq.net/blogs/ea_matters/2014/04/what-problems-does-enterprise-architecturesolve.php (accessed 03 August 2019).

Hackman, L.C. \& Knowlden, A.P. 2014, Theory of Reasoned Action and Theory of Planned Behavior-Based Dietary Interventions In Adolescents And Young Adults: A Systematic Review. Dove Press. From:

https://www.ncbi.nlm.nih.gov/pmc/articles/PMC4057331/ (accessed 06 August 2019).

Hazen. B.T., Kung, L., Cegielski, C.G. \& Jones-Farmer, L.A. 2014, Performance expectancy and use of enterprise architecture: Training as an intervention. Journal of Enterprise Information Management, (27)2: 180-196.

Hendricks, D. 2018, Being an entrepreneur can prove difficult, but understanding these 10 traits of other successful entrepreneurs should help.

https://www.inc.com/drew-hendricks/10-habits-of-the-successful-entrepreneur.html (accessed 9 May 2018).

Hon, A.H.Y. \& Lui, S.S. 2016, Employee Creativity and Innovation in Enterprises: Review, Integration, and Future Directions for Hospitality Research. International Journal of Contemporary Hospitality Management, (28)5: 862-885.

Jenkin, M. 2016, Risk in Business: Does He Who Dares Really Win? An Impulse towards Risk Taking Can Help Entrepreneurs Seize Opportunities Under Stress, But Resilience, Optimism and Timing Are Just as Important. From:

https://www.theguardian.com/small-business-network/2016/apr/18/risky-business-dares-win-entrepreneur/ (accessed 21 March 2018).

Jevtic, G. 2018, What Is High Availability Architecture? Why Is It Important? From:

https://phoenixnap.com/blog/what-is-high-availability (accessed 7 May 2019).

Johnson, B., Turner, L.A. \& Christensen, L.B. 2011, Research Methods, Design, and Analysis. London: Pearson.

Kamleitner, B., Korunka, C. \& Kirchler, E. 2012, Tax Compliance of Small Business Owners: A Review. International Journal of Entrepreneurial Behavior \& Research, (18)3: 330-351.

Kharytonov, S. \& Sukholeyster, O. 2012, Enterprise It Architecture: Goals, Trends And Perspectives. http://sandhill.com/article/enterprise-it-architecture-goals-trends-and-perspectives/ (accessed 19 December 2018).

Køien, G.M. 2020, A Philosophy of Security Architecture Design. From:

https://link.springer.com/article/10.1007/s11277-020-07310-5 (accessed 7 May 2019).

Kuhn, K., Galloway, T. \& Collins-Williams, M. 2016, Near, Far, And Online: Small Business Owners' Advice-Seeking from Peers. Journal of Small Business and Enterprise Development, (23)1: 189-206.

Lamb, H., McDaniel, B., Terblanche, E. \& Klopper. 2015, Marketing (4th edition). Cape Town: Oxford.

LaMorte, W.W. 2018, Diffusion of Innovation Theory. Boston University School of Public Health. From:

http://sphweb.bumc.bu.edu/otlt/MPH-Modules/SB/Behavioral ChangeTheories/BehavioralChangeTheories4.html (accessed 02 April 2019).

Le, D. 2020, Scalable Web Architectures Concepts \& Design. From:

https://medium.com/distributed-knowledge/scalable-web-architectures-concepts-design-6fd372ee4541 (accessed 7 May 2021).

Lewis, S. 2019, Interoperability. From: https://searchapparchitecture.techtarget.com/definition/interoperability (accessed 7 May 2019).

Liu, Y. 2017, Risk-Taking and Persistence Make Successful Entrepreneurs, Says Sequoia's Shen. From: http://www.scmp.com/business/money/markets-investing/article/2113463/risk-taking-and-persistencemake-successful/ (Accessed 21 March 2018).

Llinares, C., Montañana, A. \& Navarro, E. 2011, Differences in Architects and Nonarchitects' Perception of Urban Design: An Application of Kansei Engineering Techniques. From:

https://www.researchgate.net/publication/258380532_Differences_in_Architects_and_Nonarchitects'_Perception_of _Urban_Design_An_Application_of_Kansei_Engineering_Techniques (accessed 5 August 2021). 
Lyons. K. 2017, How to Define Good Research Objectives. https://www.lipmanhearne.com/how-to-define-goodresearch-objectives/ (accessed 10 February 2019).

Mäkitalo, N., Taivalsaari, A., Kiviluoto, A., Mikkonen, T. \& Capilla, R. 2020, On Opportunistic Software Reuse. From: https://link.springer.com/article/10.1007/s00607-020-00833-6 (accessed 7 May 2021).

Martin, G. 2019, The Meaning and Origin of The Expression: Carbon-Copy. Phrase Finder. Phrases. https:// www.phrases.org.uk/meanings/carbon-copy.html (accessed 16 June 2019).

McComb, D. 2004, Schools of Enterprise Application Architecture. From: https://www.semanticarts.com/schools-ofenterprise-application-architecture/ (accessed 5 August 2021).

Menezez, F. 2020, Application Architecture: Best Practices for Future-Proofing Your Apps. From:

https://www.outsystems.com/blog/posts/application-architecture/ (accessed 7 May 2021).

Metcalf, A. 2015, Nationwide Training Limited Were Chosen by Action for Blind People to Design an Ilm Middle Manager Leadership and Management Programme. Journal of Industrial and Commercial Training, 47(6):326 - 329.

Morosan, C. 2011, Opportunities and challenges for biometric systems in travel: a review. University of Massachusetts Amherst: International Conference. From:

https://scholarworks.umass.edu/cgi/viewcontent.cgi?article=1686\&context=ttra (accessed 30 January 2019).

Mutopo. P. 2016, Description of the Study Area in Women, Mobility And Rural Livelihoods In Zimbabwe. https://brill.com/view/book/9789004281554/B9789004281554-s004.xml (accessed 07 February 2019).

Ndiaye, N., Abdul, L., Ruslan, R. \& Adam, N. 2018, Demystifying Small and Medium Enterprises' (SMEs) Performance In Emerging And Developing Economies. From:

https:// www.sciencedirect.com/science/article/pii/S2214845018300280 (accessed 7 May 2021).

Omale, G. 2019, 8 Steps for a High-Impact Enterprise Architecture Program. From:

https://www.gartner.com/smarterwithgartner/8-steps-for-a-high-impact-enterprise-architecture-program/ (accessed 6 September 2021).

Pavlenko, I. 2021, Web Architecture: Why Is It Important? From: https://light-it.net/blog/web-app-architecturewhy-is-it-important/ (accessed 07 May 2021).

Post, J. 2017, What Traits Do the Most Successful Entrepreneurs Have in Common?

https:// www.businessnewsdaily.com/8128-traits-of-successful-entrepreneurs.html (accessed: 9 May 2018).

Power, D. 2008, What are challenges of real-time decision support? From:

http://dssresources.com/faq/index.php?action=artikel\&id=178 (accessed 10 May 2018).

Rana, G, Goel, A.K. \& Rastogi, R. 2013, Talent Management: A Paradigm Shift in Indian Public Sector. Strategic HR Review, (12)4: 197-202.

Rhodes, P. \& Bryant, J.H. 2019, Public Health. Encyclopedia Britannica. https://www.britannica.com/topic/publichealth (accessed 02 April 2019).

Roberts, K.A. \& Wilson, R.W. 2002, ICT, and the Research Process: Issues around the Compatibility of Technology with Qualitative Data Analysis. http://www.qualitative-research.net/index.php/fqs/article/view/862 (accessed 19 February 2019).

Roland, K., Yeo, J., Gold, M. \& Marquardt, J. 2015, Becoming Leaderful: Leading Forward in Turbulent Times. Journal of Industrial and Commercial Training, 47(6): 285-292.

Sarri, K.K., Bakouros, I.L. \& Petridou, E. 2010, Entrepreneur Training for Creativity and Innovation. Journal of European Industrial Training, (34)3: 270-288.

Schmidt, R.F. 2013, Architectural Element: Software Control Practice. From:

https://www.sciencedirect.com/topics/computer-science/architectural-element (accessed 7 May 2021).

Schulz, W. \& Dankert, D. 2016, Governance by things as a challenge to regulation by law. From:

https://policyreview.info/articles/analysis/governance-things-challenge-regulation-law (accessed 05 February 2019).

Sebetci, Ö. 2019, Enhancing End-User Satisfaction through Technology Compatibility: An Assessment on Health Information System. Science Direct. https://www.sciencedirect.com/science/article/pii/S2211883718301412\#! (Accessed 02 April 2019).

Seth, S. 2017, 10 Characteristics of Successful Entrepreneurs. https://www.investopedia.com/articles/personalfinance/101014/10-characteristics-successful-entrepreneurs.asp (accessed 9 May 2018).

Settle, M. (2019). Managing Enterprise Application Architectures In 2020: The Game Has Changed! From: https:// www.cio.com/article/3341316/managing-enterprise-application-architectures-in-2020-the-game-haschanged.html (accessed 7 May 2021).

Sha, S. 2019, The Reliability of Enterprise Applications. From:

https://www.researchgate.net/publication/338419014_The_Reliability_of_Enterprise_Applications (accessed 8 May 2021). 
Silverman, B.G. Hanrahan, N., Haung, L., Rabinowitz, E.F. \& Lim, S. 2016, Artificial Intelligence and Human Behavior Modeling and Simulation for Mental Health Conditions.

https://www.sciencedirect.com/science/article/pii/B9780124202481000076_(accessed 06 August 2019).

Sjögrén, H., Flainen, K. \& Syrjä, P. 2011, What Does the Owner-Manager Want and Get Out of the Business? International Journal of Law and Management, (53)5: 355-374.

Sparks System \& Enterprise Architect. 2020, Sparx Enterprise Architect License Sales. From: https://realirm.com/eatools/sparx-systems-enterprise-

architect?gclid=cjwkcajwtj2fbhaueiwaiku19qhqghpjfo5sdkaulb9xehac95qjfxp9jrhis7k9onoldwibhiyoihocjw4qavd _bwe (accessed, 21 May 2021).

Spence, C. 2020, Senses of Place: Architectural Design for the Multisensory Mind. From:

https://cognitiveresearchjournal.springeropen.com/articles/10.1186/s41235-020-00243-4 (accessed 7 May 2021).

Stok, F.M., Renner, B., Allan, J., Being, H., Ensenauer, R., Issanchou, S., Kiesswetter, E., Lien, N., Mazzochi, M., Monsivais, P., Stelmach-Mardas, M., Volkert, D. \& Hoffmann, S. 2018, Dietary Behavior: An Interdisciplinary Conceptual Analysis and Taxonomy. From:

https://www.frontiersin.org/articles/10.3389/fpsyg.2018.01689/full (accessed 14 September 2021).

Sun, H. 2011, The 3-3-3 Framework And 7p Model for Teaching Creativity, Innovation and Entrepreneurship. Journal of Chinese Entrepreneurship, (3)2:159-166.

Svärd, P. 2013, Enterprise Content Management and the Records Continuum Model as Strategies for Long-Term Preservation of Digital Information. Records Management Journal, (23)3: 159-176.

Ticlo, I. 2018, 4 ways to achieve operational efficiency across your supply chain. From:

https://www.insight.com/en_US/learn/content/2018/02072018-4-ways-to-achieve-operational-efficiency-acrossyour-supply-chain.html (accessed 12 May 2018).

Tomaney, J. 2020, Reliability, Scalability and Availability - The Architectural Pillars of Payments Solutions. From: https:// www.finextra.com/blogposting/19645/reliability-scalability-and-availability---the-architectural-pillarsof-payments-solutions (accessed 7 May 2019).

Tong, K. 2019, EHR Compatibility and Connectivity: Two Obstacles to Patient Care. Ehrintelligence. https://ehrintelligence.com/news/ehr-compatibility-and-connectivity-two-obstacles-to-patient-care (accessed 02 April 2019).

Trinh-Phuong, T., Molla, A. \& Peszynski, K.J. 2012, Enterprise Systems and Organizational Agility: A Review of the Literature and Conceptual Framework. (Accessed 21 July 2019).

Valasseri, S. 2019, Top Technology Challenges Faced by Small Businesses. From:

https://www.infince.com/blog/top-technology-challenges-faced-by-small-businesses/ (accessed 6 May 2021).

Walport, M. \& Rothwell, D.N. 2013, Council for Science and Technology.

https://assets.publishing.service.gov.uk/government/uploads/system/uploads/attachment_data/file/224953/13923-age-of-algorithms-letter-to-prime-minister_1_.pdf (accessed 16 June 2019).

Wayner, P. 2020, The Top 5 Software Architecture Patterns: How to Make the Right Choice. From: https://techbeacon.com/app-dev-testing/top-5-software-architecture-patterns-how-make-right-choice (accessed 7 May 2019).

Young, S. 2012, 12 Attributes of a Good Web Application Architecture. From: https://medium.com/on-coding/12attributes-of-a-good-web-application-architecture 58e90c884fa3\#: :text=Developer\%20productivity\&text=Concise $\% 20$ but $\% 20$ not $\% 20$ obtuse,Short $\% 20$ feedback $\% 201$ loo ps (accessed 7 Many 2021).

Zaugg, H. \& Warr, M.C. 2018, Integrating a Creativity, Innovation, and Design Studio within an Academic Library. Library Management, (39) 1/2: 172-187.

Zayra, V. 2016, Men With 2 Years of Work Experience Earn More Than Women With 6. http:/ / fortune.com/2016/09/13/ivy-league-wage-gap/ (accessed 21 August 2018).

Zide, J.S., Mills, M.J, Shahani-Denning, C. \& Sweetapple, C. 2017, Work Interruptions Resiliency Toward an Improved Understanding of Employee Efficiency. Journal of Enterprisesal Effectiveness, People and Performance, (4)1:39-58. 